\title{
The Bamboo Stupa of Wat Pa'O Ram Yen: An Experiment in Local Agency
}

Geneviève Gamache, Cultural Centre, University of Malaya,

Kuala Lumpur, Malaysia

genevieve@um.edu.my and ggamac@gmail.com

(C) 2016 University of Malaya. All rights reserved.

Malaysian Journal of Performing and Visual Arts, Volume 2, 2016

\begin{abstract}
After the traumatic experience of the 1997 financial crash, an imposing 'soul searching' happened in Thailand to assess where the country had failed. This assessment gave rise to some elements of the current discourse on localism, where globalisation is pinned against rural life, which became a source of traditional values. Yet the discourse was rooted in an idealised vision of rural life, crystallised in an undetermined traditional past. The discourse failed to present the rural community as a source of transformation, change, and agency, which ultimately led to a distrust of the local as a source of contemporary relevance. This article explores a small rural temple as a community art project, where the entire village came together, under the supervision of contemporary ceramicist Somluk Pantiboon, to construct their chedi, or stupa. Similar to community and relational art, the stupa serves as a source of communal relation. The chedi is an anomaly in comparison to other Thai stupas, as it was created using criss-crossed strips of bamboo on a metal frame. This unusual choice of medium is at the centre of Somluk's concept behind the temple, which was created to bring the community together and create their own identity, as a rural community, by participating in the construction of the temple. Contrary to stereotypical constructs of the rural community in the current discourse on localism, the chedi at Pa'O Ram Yen becomes a positive symbol of the community, while the process leading to it being there helped forge the community in the 'local', yet focused on the future, rather than an idealised past.
\end{abstract}

Keywords: Wat Pa'O Ram Yen, localism, stupa, chedi, community art, bamboo

\section{Introduction}

Although small Buddhist temples are certainly common in Thailand, the temple of $\mathrm{Pa}$ 'O Ram Yen distinguishes itself from other temples in the country. Its construction started in 2006 under the artistic supervision of contemporary ceramicist Somluk Pantiboon, a respected artist whose shop and gallery are located in the village. Yet what makes this temple special is not only the fact that villagers asked a prominent 
Thai artist to help with the temple, but that the artist, in turn, insisted that the villagers themselves participated in the temple's construction.

It is this local level artistic production which will be analysed in this article. Of course, it is not to say that the temple itself, as an art and/or architectural object, is not interesting. On the contrary, I contend that the participation of a local community

${ }^{1}$ informed its artistic form, as well as the medium used in its construction.

In this article I will therefore explore the construction of the temple, particularly its chedi, and try to situate it within the discourse of localism in Thailand, paying particular attention to the intended artistic process.

\section{Stupa/Chedi}

The stupa is one of the oldest Buddhist monuments still constructed and used today. Indeed the stupa is one of the three monuments, along with the Vihāra (gathering place for monks) and the Caitya-grha (hall accessible to the community), that could be found in the earliest of Buddhist monasteries (Chihara, 1996). Nevertheless, stupas are not Buddhist in origin. They follow thousands of years old of burial mound traditions found, not only in pre-vedic India, but all over the world (Bénisti, 1960; Fussman, 1986). Furthermore, the word stupa has for its root the sanskrit word stup which means to gather or to collect. The traditional stupa is therefore a monument that resembles a mound or a pile (Bénisti, 1960). While the other two monuments of the Buddhist monastery, the Vihāra and the Caitya-grha, were associated with the monks and the lay community respectively, the stupa was, and still is today, associated with the Buddha. Indeed, according to the Mahāparinibbānasutta (DN16.6.24-28) when the Buddha died, his burnt remains were protected by seven different stupas. Later, Asoka recovered the remains and re-divided them into an even greater number of stupas, 8400, according to Asokavadana or Tale of Asoka (Strong, 1983).

Today, stupas can still be found in Buddhist monasteries all around the world, yet their names, as well as their forms and symbolisms, have changed through time and place. In Thailand for example, it is usually known as a chedi (the name rooted in the term Caitya-grha mentioned earlier), in Myanmar it is known as a Zedi, in Sri Lanka as a Dagaba, and in China as a Pagoda (Gamache, 2010). Along with their names, their forms have also changed. Pagodas for example are based on Chinese watch-towers rather than burial mounds. In Thailand, the medhi has also become the most visually imposing section of the chedi, while the anda, which was the largest section in the time of Ashoka, has been relegated to a small bell-shaped section towards the top of the now conical monument.

Although the stupa's shape varies from region to region, on the whole it remains a relatively simple architectural monument, yet it has a complex symbolism. It is this symbolism, or rather a certain lack of academic consensus regarding this symbolism, which has attracted substantial academic study. 
Over the years, the study of the stupa/chedi ${ }^{2}$ has generally fallen into two categories. On the one hand, there are those looking for 'universal' meanings and symbolisms of the stupa and, on the other, those looking at culturally and regionally specific meanings and symbolisms. For example, scholars such as Bénisti (1960), Snodgrass (1985), and Tucci (1988) tried to establish a core symbolism of the stupa, such as the stupa as a cosmogram, as the Buddha, as a symbol of royal power and as the dhamma. All these symbols are not without challenge however and not all scholars agree on the specificities of a potential core symbolism. For example, Bénisti (1960) believes that the three main symbols of the stupa are the Buddha, the cosmos and the symbol of royal power while Snodgrass (1985) sees them as the Buddha, the cosmos and the dhamma. Furthermore, some scholars such as Fussman (1986) and Woodward (1993) do not believe in a potential core symbolism that would exist independent of a specific regional architectural forms and cultural background, including the different regional Buddhist beliefs. It is therefore fair to say that, when it comes to studying the stupa or chedi, no juste milieu has been reached.

Following a more regional based type of scholarship, Byrne (1995) convincingly argues that in Thailand it is the royal patronage as well as nationalism, which are the most important symbols of the stupa or chedi. The other symbols, if indeed valid in Southeast Asia, having been transferred to other monuments. For example, in historical Lan $\mathrm{Na}^{3}$ or northern Thailand, the Buddha's presence and the dhamma are/were experienced through the Buddha's statue in the vihan (hall of the laity), rather than through the chedi. Similarly, still in northern Thailand, the most revered historical and geographical markers are the Buddha's footprints (Byrne, 1995; Gamache, 2010).

As symbols of royalty and nationalism, the material used for the construction of the Thai chedi is important, as the monuments need to represent grandeur and dignity. Indeed in Thailand, these monuments are built and restored to preserve the relation between royalty, Buddhism and the modern Nation State. Byrne (1995) talks of a "monumentalisation of the Thai past" so that the monarchy and later the State, would, by means of expensive patronage, keep Thailand's national identity intact. Although the chedi at Wat Pa'O Ram Yen can potentially be analysed as part of this Buddhist architectural legacy, the monument is particularly interesting because it locates itself more easily in a discourse on localism than one on the State.

\section{Localism}

In Thailand, studies of localism have followed the country's economical and political changes. Thongchai Winichakul (1995) asserts that the first wave of local studies in Thailand followed the 1973/1976 political crises. Thai scholars were looking for alternative perspectives to the Thai historical grand narrative, often bringing the regional historical aspects, yet following the same hierarchical model, concentrating on a top-to-bottom approach to history. According to Phongpaichit and Baker (2000), the second wave of local studies and general interest in localism burgeoned out of the 1997 financial crisis. Indeed one of the immediate consequences of the financial debacle was a regain in local identity and national pride based on the rural. 
In a post-1997 era, localism became synonymous with ruralism and rural community as a counter-part to globalisation. According to Phongpaichit and Baker (2000), localism became a moral force against globalisation, which became the scapegoat of the financial debacle. Indeed, foreign involvement in the Thai economy, or vice versa, appeared to have failed the Thai population. Prior to the 1997 financial crisis, rural life was perceived as the country's backbone, a source of morality even under hardship. On the other hand, Bangkok was presented as a centre of modernism, a necessary evil that would make Thailand a rising dragon in a global economy (Taylor, 1995; Winichakul, 1994). Yet after the financial crash, the dragon's pride was, if not crushed, severely wounded. All that remained was the rural, its backbone, to support it. As Hewison (1999) and other scholars explain (Phongpaichit and Baker, 2000; Taylor, 2008), in the immediate aftermath of the financial crash, the local community was presented as a moral and ethical construct, a guardian of past traditions previously experienced in an assumed historical golden age, now obviously lost. This type of localism based on ideological pride is what Hewison calls populist localism (1999).

Hewison explains that proponents of localism unfortunately stayed within the realm of nostalgia and failed to represent it as a practical discourse, giving ammunition to protestors who saw the discourse on localism as a veil woven through idealism hiding a corrupt local political structure. Indeed, with the economical recovery and investigations regarding political corruption, idealisation of the countryside through nostalgia only went so far. Therefore, as Walker (1999) alludes to, following the 1997 financial debacle, the rural life went from idealised moral construct, to an assumed hub of political corruption.

It is not my intention to reduce the post-financial debacle era to a mere dichotomy between the urban and the local. Yet, as Connors (2005) explains, it is this dichotomy that was, and to some extent still is, present in the media coverage and political façade of the post-financial crash period. ${ }^{4}$ However, this ideological construction of the local is generally promoted by an outsider. In other words, it is an ideological representation created from an idealised 'other' way of living, rather than an identity formation based on local agency. Somluk's vision for Wat Pa'O Ram Yen shows localism in a different light, one that is not based on a golden-age ideology of the past, but on contemporary local agency.

\section{The Temple}

The temple of Wat Pa'O Ram Yen [วัดป่าอ้อร่มเย็น, Temple of the Cool-shaded Forest] is still under construction; yet two of the three main buildings, the ubosot and the chedi, are already accessible to the laity. As Somluk explained in a personal conversation in June 2007, before 2006, with only 400 inhabitants, the village of Ram Yen did not have a temple of its own. For religious ceremonies and spiritual guidance, the population had to go to a different village. Resolved to build their own temple even in the difficult political and financial situation of 2006, the villagers asked him to help them realise their project. ${ }^{5}$ 
As an artist already established in the community-his workshop is only a few meters away from the new temple-Somluk was a logical choice for the villagers. Yet, by asking a renowned artist who is already socially engaged in the village to supervise the project rather than going with standard national blue prints ${ }^{6}$, the community ensured that not only would their temple be aesthetically different from other local temples, but that his artistic vision and theoretical approach would be reflected in its art and architecture. In other words, the local community, knowingly or not, agreed to transform the conventional religious space of the Buddhist temple into a local contemporary art experiment.

Therefore, and while he accepted to help, it was also important for him that the villagers themselves, as a community, participate in the temple's construction rather than simply pay for it. He wanted the villagers to physically participate in its construction and so he needed to find a material which they would be comfortable working with and that would suit the local community. For the chedi, he therefore chose bamboo, an organic material easily accessible by the community and used on a daily basis.

Somluk's first idea for the chedi was one of simple receding platforms of vertical bamboo posts [Prathong, et al, 2550 (Thai year)] $]^{7}$. With this design the bamboo would not only be exposed, but would resemble bamboo culms in their natural environment. He knew that when left unprotected, these bamboo posts would decay relatively quickly, within 10 to 15 years, therefore ensuring that the community would gather again in the near future to rebuild the chedi [Prathong, et al, 2550 (Thai year)]. Wary of the cost of rebuilding an architectural monument every decade or so, the original scheme was altered to make way for a chedi made from crisscrossed bamboo strips over a metal frame as seen in Figures 1 and 2. This technique also allows for a greater freedom with the shape of the chedi. Somluk was therefore able to design a structure with a more sinuous shape, slightly more reminiscent of the traditional Lan Na chedi. If left to the elements however, unprocessed strips of bamboo would decay in less than a decade, making the new project even more ephemeral than the first concept. He therefore decided to cover the structure, first with a thick unpolished layer of an experimental mixture made of lacquer and natural glue as seen in Figures 1 and 2, and second, with a layer of gold paint. As he indicated in a personal conversation on $23^{\text {rd }}$ March 2010, while the gold colour helps embellish the structure, it is his hope that the lacquer will help protect it from the rain and that the glue, made of animal hide, will protect it from the sun. Yet, this mixture is an experiment and no one knows for how long this chedi will last. The monument will therefore have to be closely monitored and most likely be refurbished or even rebuilt entirely in the near future, although the exact moment is uncertain. ${ }^{8}$ Nevertheless, and although the chedi is now covered, the primary medium cannot be forgotten, as the community was directly involved in its construction. 

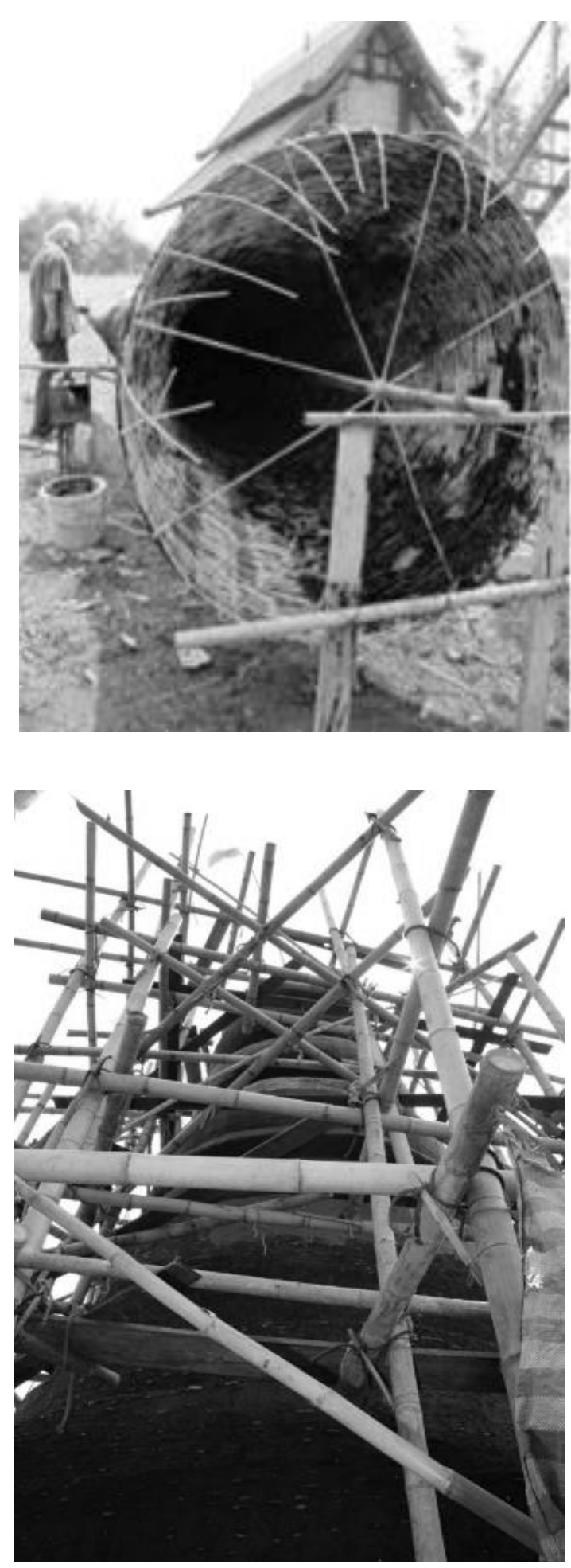

Figure 1. The image shows the upper section of the stupa still under construction. The bamboo strips are visible inside the structure (Photograph by researcher).
Figure 2. Bamboo stupa under construction. The image clearly shows the black lacquer and glue mixture on the surface of the bamboo stupa under construction. The lower part of the medhi is still lacking a final coat, so that the crisscrossed bamboo strips used to create the stupa as still visible (Photograph by researcher). 
Furthermore, most traditional chedis are imposing structures that often run counter to their environments. Made with bamboo, the chedi will also remind the local community of its surroundings since, as was mentioned earlier, bamboo is available in its raw form in the village. Somluk comments that imbalance in nature can now be witnessed around the world, not only in Thailand (Pantiboon \& Srisitanont, 2008). He believes that this imbalance is caused by people who are now disconnected from their environments. It is his hope that when people work with the chedi, they will realise the importance of nature and will be able to appreciate the bamboo growing in their own village [Prathong, et al, 2550 (Thai year)]. He wants people to realise that nature is fragile and that it is now, mostly due to human activities, out of balance. He wants them to realise that their actions have consequences. Bamboo is the perfect medium for that, since it is a grass that grows quickly. It can be harvested without great damage to the environment and without too much financial burden on the village.

This interest in nature is paralleled with his interest in Buddhism. Although the traditional Thai chedi has a complex set of symbolism, Somluk's monument brings an entirely different symbolic meaning and religious experience. As explained before, historical chedi may be seen as symbols of the Buddha and the dhamma. The unconventionality of an organic chedi teaches specific Buddhist doctrines, in this case impermanence and dependent origination, which are different than the potential core or regional stupa symbols mentioned earlier. Although 'impermanence' can be represented by Buddhist iconography, such as the wheel of Samsara, at Wat Pa'O the Buddhist concept is experienced and realised through the chedi's medium. By working and meditating on the ephemerality of organic material, either it be growing in the village or transformed for art making, the community can develop a better awareness of the Buddhist doctrine that surpasses a simple iconographic reminder.

Furthermore, art production within, or for, the space of a Buddhist temple also acts as an act of merit. As such, all practitioners, regardless of their social positions, can accumulate merit. Byrne (1995) explains that the monumentality of the chedi usually requires rich and important patrons. Indeed, as explained earlier, the Thai chedi are normally associated with royalty and the State, since they were/are primary patrons. At $\mathrm{Pa}$ 'O, the chedi could therefore potentially disrupt the hierarchical aspects of merit making and artistic patronage. Yet, I do not contend that this is Somluk's goal. At Ram Yen, the chedi is created through local agency. This does not mean that the symbolism of the State and/or nationalism are negated. One of the issues of the discourse on localism is its tendency towards absolutism and essentialism. In other words, one cannot be embracing localism if one also claims participation in the nationalist, modern, and state centred discourse. Yet the stupa is a form which, as was explained before, never worked in 'either or'. Although some readings of stupa might sometimes be stronger, such as royalty, the Buddha or indeed a historical marker, scholars studying the stupa do not negate that all the meanings are potentially present when it comes to stupa. In a way, stupas or chedis are open signifiers dependent on time and place. At times some meanings become more dominant than others, yet never negating the others. At Wat Pa'O Ram, localism becomes the dominant meaning, yet, as a Thai chedi, the relation with the State cannot be entirely negated. As such, the 
chedi at Wat Pa'O Ram Yen is a local form first, onto which other conventional symbols are residuals, yet nonetheless there. This makes the chedi an open signifier, a structure that is inclusive, rather than preferential.

Coming back to the concept of merit making, although Somluk acknowledges its importance, the villagers are not necessarily building the chedi so that they would gain or strengthen a religious identity. Though a spiritual man, Somluk's interest in this Buddhist temple is the community's self-awareness, which would be obtained through participatory art production (personal conversation, March $23^{\text {rd }} 2009$ ). Once again, this does not mean however that one automatically hinders or negates the other [Prathong, et al, 2550 (Thai year)].

In an interesting way, I put forth that the project finds itself at the intersection of community art and relational art. This is due, in part, to Somluk's understanding of the importance and relation between artistic production and social development. For example, he is well known to have worked in refugee camps in Northern Thailand, where he taught Laos refugees how to do pottery, as both an artistic relief, but also a potential source of income (Gamache, 2010). He also allows the villagers to use his kilns for their own ceramic works, and he employs a few workers in his own workshop (Gamache, 2010). In other words, art for Somluk has different values, including aesthetics, but also economical values, both important when it comes to community development.

For the chedi, I contend that the core value behind the structure was a communal one. As mentioned earlier, the plans behind the temple, including the chedi, were carefully created by Somluk, who then presented it to the villagers for approval. Yet the villagers were concerned with the first plans, and asked him to change his artistic vision for the monument. He returned to his drawing board and proposed new blueprints for the stupa which now standing in the temple compound. As such, he was responsible for the artistic concept and visual aesthetics behind the stupa. At the centre of this concept was the participation of the villagers. In a way, the form itself, although interesting, is secondary, if not residual, while the participation was central to the artistic project. As such, it is an interesting example of the 'experiential' aspect of community art (Lowe, 2002).

Community art per se started in the 1960s as a way to democratise art and 'bring back' artistic expression to the people. In other words, at the core of early community art was the democratisation and promotion of creative expression, a desire to bring artistic expression and creation to the street, instead of keeping it in the artist's studio. As such, the response and research surrounding community art has focused on its importance when it comes to the democratisation of art. Many, although not all (Duddy, 1994), studies show its importance when it comes to community building through this democratisation and community involvement in artistic expression (Allen, 1994; Lowe, 2002; Vaughan, 1999). 
Not unlike community art, as well as relational art, the chedi serves as a source of communal relation. Indeed, when witnessing the temple's construction on the temple's blog (Ajchariyasophon, 2009), we can see that elderly, students still in their high school uniforms, office workers wearing shirts and ties, even the monks themselves, are active participants in the temple's construction, including the chedi's. In a way, the construction and the maintenance of the temple, especially the chedi, act as what Featherstone (1996) calls 'ceremonies and rituals,' which help hold the local community together. What is interesting here however, is that it is the making of the chedi, the artistic process itself, and not religious ceremonies around it, that gathered the community together.

Contrary to early community art project however, Somluck's interest in the temple and the stupa in particular was not necessarily in the creation of popular art, rather than high-art, art, but in the relation that was created through participation. In this way, his interest in community art is closer to relational art, rather than community art of the 1960s through the 1980s when community art was seen as the anti-thesis to High-Art. What Dickson calls the community artists" "dislike of cultural hierarchies" (1995, p. 18 ) is not necessarily shared by Somluk, who is an active participant in many different artistic circles, including museums, galleries and the international artistic community. Yet it would be wrong to say that the artistic product is not important, on the contrary. The villagers created a stupa, which is an important signifier of Buddhism and social hierarchy in Thailand. There is therefore a process of democratisation in its creation, as it is a community, and not important the State and royal patrons, that are behind its creation. As such, and because there is an important, and in this case, imposing, art object at the end of the social relation, the project is closer to community art, than relation art. Indeed contrary to Rirkrit's relational art experiments, such as his cooking of pad thais in museums, where there is no residual object, at Wat Pa'O Ram Yen, the villagers are left with a chedi.

Yet, community art is more than a need to create something transgressive to the hierarchy of the art world. It also includes the importance of bringing back, although guided by the artist, the concept of creativity and artistic expression to the community (Drury, 1991/1992; Lowe 2002). This is why the chedi as Wat Pa'O Ram Yen is at the junction between community art and relational art, since the aesthetic experience based on expressive creativity was not necessarily at the core of the community's experience. In other words, it was the participation itself that was important, rather than personal artistic expression of the participants, which was not part of the project. As such, the project is missing an important core value behind the concept of community art, and is therefore closer, to relational art, at least when it comes to personal artistic expression.

Another important aspect of community art is that it gives a platform to express "grassroots issues and messages" (Lowe, 2002). As such, Somluk's interest in ecological issues is important, and ties it neatly with community art. Indeed, as was mentioned earlier, it was his hope that the community would feel a rapprochement with their environment due to their manipulation of the bamboo while making the stupa. Yet this platform is secondary to the importance of the communal relation itself. 
Furthermore, though the village already existed before the chedi was built, the difficult political situation of the post-financial crash era, especially when it comes to social relations between the local and the urban, brings a different dimension to the chedi's artistic importance. This chedi can potentially extricate local identity from one of stagnation and stereotypification experienced in the first moments of the financial crash's aftershock, where local identity was created by outsiders to the local, presenting it as a passive guardian of traditions, as a source of unchanging identity and historical values, rather than active, modern ones. Contrary to these stereotypical constructs, the Ram Yen community is active in creating its own identity through artistic relations. The chedi becomes a positive symbol of this community, while the process leading to it being there helped forge the community in the 'local'. In this context, the bamboo chedi acts as a present and future communal force, not as a guardian of past traditions. It is a monument that leads forward, not backward, as the post financial crash too often did.

In conclusion, the chedi locates itself in a difficult historical moment, where discourses on localism can act as destabilising as well as regenerative forces. Furthermore, the project posits an ever-changing model of cause-and-effect. The residue of the communal relation, the chedi will act as a marker of this relation. Indeed it will act as a barometer, not only of Somluk's teachings, such as ecology and Buddhism, but also of the community's strength itself. How, and if, the chedi is rebuilt and maintained, will act as a test of the artistic project. Yet, more so than at Rirkrit's relational art projects, such as the Land Foundation, where the lot is now under the supervision of a caretaker, the chedi will be a test of its own relational success, as it is now the responsibility of the local community. It will only 'survive' if the population is still strong and decides to gather again to rebuild or renovate it. This also means that the community will be able to adapt the structure as they see fit, changing its medium, shape or colour. As the community changes, the transformative power of the chedi will act as a marker of these changes and will not be stagnant or fixed in time.

The temple's construction and survival is therefore based on its contemporary applicability, since its aesthetic construct centres on the local community's artistic experience leading to self-awareness. The only way the chedi would stop being a contemporary art object, is if the social relation, the communal experience, failed.

\section{Endnotes}

${ }^{1}$ Localism is not automatically associated with rural community. Different scholars look at localism differently. Early scholarships, until around the 1960s, associated localism with determinism and specific rural locations, looking at what made these community unique. In the 1980 s the term localism was transformed to refer less to uniqueness and determinism, but a process of assertion. 
2 The terms chedi and stupa are not necessarily synonymous. For example, in Thailand, the term chedi is used for Thai monuments, while stupa is used for nonregional monuments. Furthermore, the term chedi refers to the form of the monument more than its function. In other words, the term has structural implication onto which are attached other meanings and symbolisms (Gamache, 2010).

${ }^{3}$ Lan $\mathrm{Na}$ is the name of an ancient kingdom, or, rather, an agglomeration of city-states, which territories loosely correspond to modern-day northern Thailand (Gamache, 2010).

${ }^{4}$ Walker's study of northern politic is an interesting exception, as he unravels the political rhetoric from a regional northern perspective.

${ }^{5}$ Somluk produces stoneware at Pa'O Yen since the early 1990s. He previously studied ceramic in Japan as an apprentice under Iwao Onuma and the Tarouemon Nakazato. He has had numerous solo and group exhibit at home and abroad. He also has received numerous prizes, including three prices at the Asian Exhibition of Arts and Crafts in Fukuoka and one Award of Merit at the $19^{\text {th }}$ Fletcher Challenge Award Exhibition in Auckland, New Zealand.

${ }^{6}$ State approved standard blueprints are available through the Thai government. These blueprints are economical, only 200 baht a set. Since these blueprints are for temples in the Bangkok style, they helped with the standardisation of Thai Buddhist architecture since the Sangha acts of 1941 and the 1962 (Gamache, 2010).

${ }^{7}$ Ponwat Prathing and others wrote Somluk's early concepts and ideas for the temple project in a small booklet of which only 100 copies were made. This small booklet is only in Thai and was printed for the population, friends and potential patrons interested in the project. Four of his friends are responsible to put his ideas in writings. Somluk acknowledges that he is not computer savvy, so his friends offered to help with the booklet. Yet the ideas and concepts written in the booklet are his.

${ }^{8}$ In an interview Somluk indicated that this mixture could indeed prove to be very efficient against the elements. The chedi could therefore last for an astonishingly long time.

\section{References}

Ajchariyosophon, A. (December 20, 2008). Wat Pa'O Ram Yen. http://watromyen.blogspot.com/2009_12_01_archive.html 
Bénisti, M. (1961). Étude sur le stupa dans l'Inde ancienne. Bulletin de l'École Française d'Extrême-Orient, (1), 37-116.

Bowie, K.A. (1992). Unraveling the Myth of the Subsistence Economy: Textile Production in Nineteenth Century Northern Thailand. Journal of Asian Studies, (4), 797-823.

Byrne, D. (1995). Buddhist Stupa and Thai Social Practice. World Archaeology, 27(2), 266-281.

Cate, S. (2003). Making Merit, Making Art. A Thai temple in Wimbledon. Honolulu: University of Hawai'i Press.

Chanjaroen, C. (1993). Strange Encounters. ArtLink, 13(3\&4).

Chihara, D. (1986). Hindu-Buddhist Architecture in Southeast Asia. (R.W. Giebel, Trans.) Leiden, New York and Köln: E.J. Brill.

Chiu, M. and Benjamin G. (2010) Asian Art Now. New York: The Monacelli Press.

Connors, M.K. (2005). Democracy and the Mainstreaming of Localism in Thailand. In Southeast Asian Responses to Globalization. Restructuring Governance and Deepening Democracy. F.L. Kok and J. Ojendal (Eds.). Copenhagen: Nias Press.

Dreeszen, C.A. (1994). Reimagining Community: Community Arts and Cultural Planning in America (Unpublished Doctoral Dissertation). University of Massachusetts, Amherst.

Drury, M. (1991/1992). Community Arts: Defined but Denied. The Irish Review (11).

Duddy, T. (1994). Art \& Society: Tom Duddy Analyses the Community Arts Idea and the Politics of Creativity. Circa (67).

Featherstone, M. (1996). Localism, Globalism and Cultural Identity. In R. Wilson \& W. Dissanayake (Eds.), Global-Local: Cultural Production and the Transnational imagery (pp. 46-77). Durham: Duke University Press.

Fussman, G. (1986). Symbolisms of the Buddhist Stupa. The Journal of the International Association of Buddhist Studies, 9(2), 37-53.

Gamache, G. (2010). Between Localism and Nationalism: Two contemporary examples of Thai Temple Art and Architecture in Northern Thailand (Unpublished Doctoral Dissertation). University of Victoria, Victoria. 
Hewison, K. (1999). Localism in Thailand: A study of globalisation and its discontents. CSGR Working Paper (39/99).

Kwon, M.(1998)Site Specificity and the Problematics of Public Art: Recent Transformations at the Intersection of Art and Architecture. Princeton: Princeton University Press.

Lower,S. (2002) The Art of Community Development (Unpublished doctoral dissertation). University of Colorado, Denver, Colorado.

Pantiboon, S., \& Srisitanont, M. (2008). A Seed of Hope. In The Still Voice of the Forest by Somluk Pantiboon. Bangkok: Ardel Gallery of Modern Art.

Prathong, P., Peugoudom, S., Sheujetton, D., \& Atchariyasopon, A. (2550 Thai year). The temple of Pa'O Ram Yen.

Phongpaichit, P., \& Baker, C. (2000). Thailand's Crisis. Chiang Mai: Silkworm Books.

Rasdjarmrearnsook, A. (2000). A narrative of an even that had just come to an end. ArtLink, 20 (2).

Snodgrass, A. (1985). The Symbolism of the Stupa. Studies on Southeast Asia. Ithaca: Cornell Southeast Asia Program.

Stallabrass, J. (2004). Contemporary Art, A Very Short Introduction. Oxford: Oxford University Press.

Strong, J.S. (1983). The Legend of King Asoka. A Study and Translation of the Asokavadana. Princeton: Princeton University Press.

Taylor, J. (2008). Buddhism and Postmodern Imaginings in Thailand. The Religiosity of Urban Space. Surrey and Burlington: Ashgate.

Tucci, G. (1988). Stupa; Art, Architectonics and symbolism. New Delhi: South Asia Books.

Vaughan, T.A. (1999). Art and Community: A Community Art Center in Norman, Oklahoma (Unpublished Doctoral Dissertation). Indiana University, Bloomington.

Walker, A. (n.d.). Charles Keyes on Sondhi Limthongkul. New Mandala. Retrieved from http://rspas.anu.edu.au/rmap/newmandala/2006/11/17/charles-keyes-on-sondhilimthongkul/ (accessed Sept $\left.1^{\text {st }}, 2009\right)$ 
Winichakul, T. (1994). Siam Mapped. A History of the Geo-Body of a Nation.

Honolulu: University of Hawai'i Press.

Winichakul, T. T. (1995). The Changing Landscape of the past: New Histories in Thailand since 1973. Journal of Southeast Asian Studies, 26(1), 99-120.

Woodward, H. W. J. (1993). The Thai "Chedi" and the Problem of Stupa Interpretation. History of Religions, 33(1), 71-91. 